\title{
FATIGUE LIFE METHODOLOGY FOR TAPERED HYBRID COMPOSITE FLEXBEAMS
}

\author{
Gretchen B. Murri*a ${ }^{\mathrm{a}}$, Jeffery R. Schaff ${ }^{\mathrm{b}}$ \\ ${ }^{a}$ U.S. Army Research Laboratory, Vehicle Technology Directorate, NASA Langley Research C enter, Hampton, VA \\ 23681

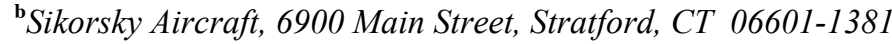

\begin{abstract}
Nonlinear-tapered flexbeam specimens from a full-size composite helicopter rotor hub flexbeam were tested under combined constant axial tension and cyclic bending loads. Two different graphite/glass hybrid configurations tested under cyclic loading failed by delamination in the tapered region. A 2-D finite element model was developed which closely approximated the flexbeam geometry, boundary conditions, and loading. The analysis results from two geometrically nonlinear finite element codes, ANSYS and ABAQUS, are presented and compared. Strain energy release rates $(G)$ associated with simulated delamination growth in the flexbeams are presented from both codes. These results compare well with each other and suggest that the initial delamination growth from the tip of the ply-drop toward the thick region of the flexbeam is strongly mode II. The peak calculated $\mathrm{G}$ values were used with material characterization data to calculate fatigue life curves for comparison with test data. A curve relating maximum surface strain to number of loading cycles at delamination onset compared well with the test results.
\end{abstract}

Key words: flexbeam, A: polymer matrix composite, B: fatigue, fracture toughness, C: delamination

\section{INTRODUCTION}

Polymeric composites are used to manufacture hingeless, bearingless composite rotor hubs for helicopters. These components are made of fewer parts and offer the advantages of reduced weight and drag, compared to metal hubs. During flight, these rotor hubs experience constant axial tension load from the centrifugal forces, and transverse bending in the flapping flexure region. In order to accommodate bending loads, composite flexbeams use internal ply-drops to create a non-linear taper. However, these internal ply-drops create material and geometric discontinuities, which are sources of delamination onset [1-6]. An analysis and test methodology that incorporates damage, failure initiation and growth, and failure probability is critical to demonstrate reliability for new and existing rotor hub designs.

One approach to life prediction in structural composites is to simulate damage in structural analytical models and use fracture mechanics based techniques to calculate strain energy release rates, as proposed by 
O'Brien in ref. 7 and summarized by Martin in ref. 8 . In ref. 6, this approach was used to correctly calculate the fatigue life to onset of delamination for coupon-size tapered flexbeams under tension-bending cyclic loading.

In ref. 9, the effect of combined tension-bending loading on hybrid graphite/glass-epoxy laminates with a nonlinear taper was studied. Test specimens of two different hybrid configurations were cut from a full-size helicopter tail-rotor flexbeam and were tested in a hydraulic load frame under combined constant axialtension load and transverse cyclic bending loads. Two-dimensional finite element (FE) models of the hybrid layups were developed, and combined axial tension and cyclic bending loading was applied. The models were able to duplicate the global behavior of the test specimens in terms of displacement and surface strains. Delamination was simulated in one of the models to duplicate the observed delaminations from the experiments. The model was analyzed using both the ANSYS [10] and ABAQUS [11] finite element programs, to determine the effects of differences in the analyses. Strain energy release rate results from the two programs showed the same trends, and peak values differed by 5-11\%. Fatigue data from mode II material characterization tests was used with the calculated $\mathrm{G}$ results to calculate a curve relating transverse bending load, $\mathrm{V}$, and cycles to delamination onset, $\mathrm{N}$, for one hybrid type. No comparisons with the test data were made, because there was only one tested specimen of this hybrid type, and the delamination onset was not recorded.

The objective of this study was to improve the life prediction analysis, validate analytical tools, and resolve differences in previously reported [9] strain energy release rate calculations for the tapered hybrid flexbeams. The FE models developed in ref. 9 were used to calculate strain energy release rates for both hybrid composite laminate configurations and to determine the cause for calculated differences between the two FE analysis programs. The strain energy release rate results from the modified analyses were used to calculate delamination onset life for both hybrid types. Flexbeam coupon specimens were tested in this study, and fatigue lives were compared to the calculated results. One specimen was monitored throughout the fatigue testing using a computer-controlled digital camera, to determine whether delamination onset could be detected through visual inspection of photographs. 


\section{$\underline{\text { Test specimens }}$}

\section{EXPERIMENTS}

The flexibility requirements of the flexbeam are achieved by varying the beam thickness and ply stacking sequences along its length. Coupon-size specimens were cut from the outboard taper region of full size flexbeams from a commercial Sikorsky tail rotor. An edge-view of a typical specimen is shown in Fig. 1. The specimens had a nonlinear taper design and were symmetric about the midplane. The specimen thickness varied from 129 plies at the thick end, to 39 plies at the thin end. The layup consisted of 0,45 , and -45 degree plies, with continuous 0 -degree belt plies along the beam length. In the specimen shown in Fig. 1, the constant thickness thin section has only 0-degree plies, the tapered section is made of unidirectional and offaxis plies added in steps along the length, and the uniform thick section has unidirectional and off-axis plies. The ply terminations occurred in stepped pairs of either $45 /-45$ plies, or 4 -ply groups of [ $\left.0_{2} / 45 /-45\right]$. The specimens were fabricated using a combination of glass/epoxy and graphite/epoxy material systems. Material properties and nominal ply thickness for both materials are given in Table 1.

The Sikorsky tail rotor was manufactured such that at certain ply-layers near the midplane, the material changed across the width of the flexbeam, from graphite/epoxy near the edges, to glass/epoxy at the center. Therefore, when the flexbeams were cut lengthwise into test specimens, two different types of hybrid coupon specimens resulted. The configurations were identical except for the material type used in the plies closest to the midplane. Specimens using graphite/epoxy plies near the mid-plane are designated graphite-midplane specimens (GRMS) and those using glass plies near the midplane are referred to as glass-midplane specimens (GLMS). The exterior taper geometry was the same for both the GRMS and GLMS specimens. Total specimen gage length was $203.2 \mathrm{~mm}$ (8-inch) for the GRMS specimens and $165.1 \mathrm{~mm}$ (6.5-inch) for the GLMS specimens. For both gage lengths, the length of the tapered region was $80.7 \mathrm{~mm}$ (3.17 in.). For all test specimens, the thick region was completely within the bottom grip of the test machine. The nominal specimen dimensions are also shown in Fig. 1.

A photograph of the tapered region of a GLMS specimen edge is shown in Fig. 2. The material hybridization, as well as the continuous belt-plies and the dropped-ply groups are evident in the figure. Details of the overlapping ply-drop pattern, are shown in the sketch in Fig. 2. Each dropped-ply was 
assigned a number label; ply-drops 111 and 311 are indicated in the figure and are referred to later in this report.

\section{$\underline{\text { Test Apparatus }}$}

The flexbeam specimens were tested in a servo-hydraulic load frame, called the Axial-Tension Bending (ATB) machine. The ATB applies a constant axial tension load combined with cyclic transverse bending deformation, resulting in a constant membrane load in the specimen. Details of the ATB machine can be found in refs. 6 and 9.

In order to determine the onset of delamination, specimens must be constantly monitored during the fatigue loading. To minimize the effort, and yet to carefully monitor the actual onset of the delamination, a digital camera was used to record the delamination progression in one of the GRMS specimen tests. The camera has a $1 \mathrm{~K}$ by $1 \mathrm{~K}$ resolution, with a shutter speed of 15 frames/second. The camera was computer controlled to record an image at designated loading-cycle intervals. Each photograph was taken at the specimen's maximum transverse deflection. Photographs were recorded at every 900 cycles (every 300 seconds). All test specimens were also monitored for delamination onset and growth by periodically stopping the test and performing a visual inspection using a hand-held magnifying glass. Once delamination onset was detected visually, a ruler was used to measure delamination lengths on the surface of the flexbeam, to the nearest $\mathrm{mm}$, and the measurements were recorded.

\section{$\underline{\text { Static Tests }}$}

Before testing, the specimens were instrumented with back-to-back strain gages along the length of the flexbeam as shown in Fig. 1. The strain gages were located near ply-drop locations. The specimens were inserted into the lower grip of the test machine so that the thick end was completely within the fixed bottom grip, and the bottom of the tapered region was flush with the top of the lower grip.

Prior to fatigue testing, each specimen was tested under static load to determine the relationship between applied loads and specimen deflection and surface strains. A constant axial tension load, P, was applied, followed by a transverse displacement, $\square$, which was applied, in steps of approximately $2.54 \mathrm{~mm}(0.1 \mathrm{inch})$, up to a maximum stroke of $45.7 \mathrm{~mm}$ (1.8 inch). At each step, the surface strains along the length were 
recorded. The relationship between the bending load and resulting surface strain was used later to determine transverse displacements required to achieve the desired strain level for subsequent fatigue testing.

\section{$\underline{\text { Fatigue Tests }}$}

Since the boundary conditions of the ATB differ from those of the full-scale flexbeam in the hub, it is more logical to control the fatigue tests to a desired maximum surface strain, than to a prescribed flapping angle. Axial tension load for each specimen was determined by applying a load until the strain in the thin region reached approximately 2500 ㄷ. Then, with the axial load held constant, a transverse displacement was applied quasi-statically until the desired maximum strain level was reached in the tapered region at gages 2 or $2 \mathrm{a}$ in Fig. 1. This region was chosen for comparison with Sikorsky's baseline full-scale flexbeam test data, which references strains at locations with internal ply-drops. Asymmetric loading, with an R-ratio ( $\square_{\min } / \square_{\max }$ ) of approximately $\mathrm{R}=0.1$ was used in this study, rather than fully-reversed loading, to more accurately simulate the loading experienced by the flexbeam in flight. The transverse stroke was applied as a sinusoidal function with a frequency of $3 \mathrm{~Hz}$. The maximum strain level for each test specimen is listed in Table 2. The loading or strain levels chosen for testing were accelerated and not representative of typical flight conditions. Using accelerated load levels, the test duration could be held at less than 10E6 cycles at 3 $\mathrm{Hz}$.

\section{ANALYSIS}

\section{$\underline{\text { Finite Element Model }}$}

The finite element models used in this study to represent the GRMS and GLMS flexbeams were created in ref. 9. The models were identical, with the exception of the added length of the thin section of the GRMS model, and the different material properties used for the plies near the midplane. The models duplicate the nonlinear tapered geometry of the flexbeam and the boundary conditions of the loading apparatus. A schematic of the GLMS model is shown in Fig. 3, including a close-up of the representation at a typical dropped-ply. The models were 2-D and symmetric about the midplane. Individual plies were modeled in the outermost dropped-ply regions, using square elements and one element per ply. The locations of the dropped-plies were determined from design drawings. Resin pockets at the tips of each dropped-ply were represented in the models by a right-triangular region as shown in the inset in Fig. 3. In contrast, the plies 
near the centerline are coarsely modeled, using three layers of elements on each side of the midplane, and smeared material properties.

The elastic constants given in Table 1 were used with laminated plate theory to determine the threedimensional orthotropic properties, i.e., x-z plane, required by the analysis codes. Laminated plate theory was also used to calculate smeared properties in the coarsely meshed regions. In order to assign the material properties correctly in the tapered region, the local tangential-normal (t-n) element coordinate system was used to assign material properties for each element, as shown in Fig. 3. Fixed-end conditions were simulated at the thick end of the models. The axial tension load was applied to the thin end of the models as a distributed load and the transverse bending was applied as a prescribed displacement. In ref. 9, a mesh refinement study determined that increasing the number of elements-per-ply at the ply-drop locations from one to eight increased the calculated $\mathrm{G}_{\mathrm{I}}$ and $\mathrm{G}_{\mathrm{II}}$ values by less than $4.7 \%$. Therefore, a mesh using 1 elementper-ply was considered to have the required accuracy for this analysis.

\section{$\underline{\text { Strain Energy Release Rate Computation }}$}

In order to simulate a delamination in the flexbeam, multi-point constraint (MPC) nodes were incorporated in the model at the interfaces around the dropped-plies where delamination onset occurred. Delaminations were then simulated at those interfaces by incrementally releasing the MPCs. The Virtual Crack Closure Technique (VCCT) [12] was used to calculate strain energy release rates at each step of simulated delamination growth. The VCCT uses the forces at the delamination tip, and the relative displacements behind the delamination tip, to calculate the mode I (opening) and mode II (sliding shear) components of strain energy release rate $\left(\mathrm{G}_{\mathrm{I}}\right.$ and $\mathrm{G}_{\mathrm{II}}$, respectively). The equations for $\mathrm{G}_{\mathrm{I}}$ and $\mathrm{G}_{\mathrm{II}}$, are

$$
G_{I}=\frac{1}{2 \square a}\left(F_{y i}^{\prime} \square v_{m}^{\prime}+F_{y j}^{\prime} \square v_{l}^{\prime}\right) \text { and } G_{I I}=\frac{1}{2 \square a}\left(F_{x i}^{\prime} \square u_{m}^{\prime}+F_{x j}^{\prime} \square u_{l}^{\prime}\right)
$$

where the forces at nodes $\mathrm{i}$ and $\mathrm{j}$, and the displacements at nodes 1 and $\mathrm{m}$, all in the local $\mathrm{t}-\mathrm{n}$ coordinate system, are shown in Fig. 4. These nodal forces and displacements were obtained from the finite element analysis output files. Because these flexbeams experience large deflections, the displacements and forces must be measured in the local coordinate system; i.e., the t-n coordinate system for the deformed elements (see Fig. 4), rather than the global coordinate system. Details of these calculations are given in refs. 12 and 
13. Total strain energy release rate, $\mathrm{G}_{\mathrm{T}}$, is obtained by summing the individual mode components. Hence, $\mathrm{G}_{\mathrm{T}}=\mathrm{G}_{\mathrm{I}}+\mathrm{G}_{\mathrm{II}}$, since $\mathrm{G}_{\mathrm{III}}=0$.

\section{$\underline{\text { ABAQUS and ANSYS finite element analyses }}$}

Calculated strain energy release rate values are a critical component of the fracture-mechanicsbased methodology that was introduced in ref. 6 and used here to predict fatigue life. Therefore, it is important to understand the differences in the reported calculated $G$ values from the ABAQUS and ANSYS FE analyses in ref. 9. These FE programs differ in their implementation of element coordinate systems, orthotropic materials, constraint equations, and solution algorithms. However, both codes used a nonlinear solution with stress stiffening, surface-to-surface contact, and large deformation options. In ref. 9, the ABAQUS analysis used the CPE8 element, a 2-D 8-noded biquadratic plane-strain element. Peak strain energy release rate results from ABAQUS and ANSYS analyses for the GRMS model were shown to differ by 5 to $11 \%$ throughout the delamination growth. For this study, the ABAQUS element was changed to the CPE8R, which is identical to CPE8, but with reduced integration. Reduced integration elements "generally yield more accurate results than the corresponding fully-integrated elements " [11]. The ANSYS analysis used the PLANE82 element, an 8-noded plane-strain structural solid element with 2 x 2 reduced integration.

\section{RESULTS AND DISCUSSION}

\section{$\underline{\text { Fatigue Tests }}$}

Combined tension-bending fatigue testing was performed on three GRMS-type specimens (GRMS1, GRMS2, GRMS3), and four GLMS-type specimens (GLMS1-3 and GLMS6). Applied displacements and the resulting maximum surface strains and R-ratio, for each of the tested flexbeams are listed in Table 2. Tests were stopped periodically and specimens were visually inspected on both edges for delamination onset and growth. For all specimens, initial delamination occurred at approximately $38 \mathrm{~mm}$ from the bottom grip, 
at the ply-drop location designated as ply-drop 311 in fig. 2. Also, delamination was visible on both sides of the specimen, at the same location, and had the same general appearance.

A representative photo of delamination in specimen GLMS3 after N=61,614 loading cycles is presented in fig. 5. Delaminations started at three distinct ply-drop locations. First, a crack formed between the tip of the dropped ply nearest the surface (ply-drop 311) and the adjacent resin region. Then, delaminations grew from there toward the thick end of the flexbeam, initially along the interface toward the midplane, and then also along the interface toward the surface. As the loading continued, a second crack formed between the resin and dropped-ply tip at another location, closer to the thick end. Delaminations grew from the second crack toward the thick end, and along both interfaces around the dropped-ply. There is also a short delamination along the interface ahead of the resin pocket, toward the thin region. Continued loading resulted in delamination initiating and growing from a third ply-drop, as shown in Fig. 5. This delamination pattern was typical for all the flexbeams tested. In all cases, the delamination growth was slow and stable. Some tests were allowed to continue until extensive delaminations occurred at multiple interfaces. However, none of the specimens reached an accumulated damage state at which catastrophic failure occurred.

A photomicrograph of the area around ply-drop 311 in a delaminated specimen is shown in Fig. 6. For every tested specimen, delamination began as a crack between end of the dropped-ply and the adjacent resin region. Delaminations would then grow along any of three possible interfaces, as defined in Fig. 6 . The interface under ply-drop 311(toward the midplane) is designated interface $b l$, the interface above 311 (toward the surface) is designated interface $b$, and the interface forward from the tip of the resin pocket toward the thin region of the flexbeam, is designated interface $a$. Experimental observation indicated a preference for growth along interface $b l$, compared to interfaces $a$ and $b$, for all the test specimens.

Digital photographs were taken of the GRMS3 specimen at every 900 cycles throughout the fatigue testing. The photos were examined and the delamination onset and growth results were compared to the measured delamination lengths that were recorded throughout the fatigue testing. Based on visual inspection, delamination was initially detected at ply-drop 311 , at $\mathrm{N}=488,993$ cycles. However, delamination at plydrop 311 is not clear in the photos until about $\mathrm{N}=973,528$ cycles, when the measured delamination length 
was $3 \mathrm{~mm}$. As the delamination grew, it became more distinct in the photographs and subsequent delaminations developing at other interfaces were easily detected.

$\underline{\text { Strain Energy Release Rate Analysis }}$

In this work, the strain energy release rate analysis had three purposes: quantify preferential location of delamination at a ply-drop location, identify a preferential delamination path from a chosen ply-drop location, and predict the onset of delamination. In order to calculate strain energy release rates associated with delamination growth, delaminations were simulated in the models by incrementally releasing multipoint constraints along the delamination interfaces, and calculating the strain energy release rate at each increment. The crack behind the resin region, shown in Fig. 6, was modeled using separate uncoupled nodes at the mid-side node location on adjoining elements.

To determine the ply-drop group at which delamination initiates, strain energy release rate results from the ANSYS GRMS model were calculated at locations 111 and 311, for delaminations growing along paths $a, b$, and $b l$, with axial load $\mathrm{P}=42.52 \mathrm{kN}$ (9560 lbs.) and bending load $\mathrm{V}=-8.76 \mathrm{kN}\left(-1970 \mathrm{lbs}\right.$.). Figure 7 shows $\mathrm{G}_{\mathrm{I}}$ and $\mathrm{G}_{\text {II }}$ results for dropped-ply 111 along paths $a, b$, and $b l$. In this analysis, the peak G value, $73 \mathrm{~J} / \mathrm{m}^{2}(0.417$ in-lb/in ${ }^{2}$ ), corresponds to $\mathrm{G}_{\mathrm{I}}$ along path $a$ at ply-drop 111. The ANSYS results at ply-drop 311, shown in Fig. 8 , are approximately an order of magnitude higher than the corresponding calculations for ply-drop 111. These results suggests that delamination is more likely to initiate at ply-drop 311 than at 111 . The tests confirmed this result, as all the specimens developed initial delamination at ply-drop 311.

In Fig. 8 , the $\mathrm{G}_{\mathrm{II}}$-value for delamination along $b$ or $b l$ was primarily mode II, with $\mathrm{G}_{\mathrm{II}}$ along $b l$ reaching a peak of $711 \mathrm{~J} / \mathrm{m}^{2}$. The G-values for delamination along $a$ are small compared to the other interfaces, and are primarily mode I. A comparison of the peak G-values along each interface in Fig. 8 indicated that a delamination from ply-drop 311 was most likely to grow first along interface $b l$. This trend was consistent with experimental observations, which showed the delamination growing along interface $b l$ first in all the specimens.

The corresponding ABAQUS results for the GRMS material with a delamination starting at 311 are shown in Fig. 9. The trends are identical to the ANSYS results, with highest values for the $b l$ interface, and primarily mode II delamination along $b$ and $b l$, and mode I delamination along interface $a$. 
Strain energy release rate results from the ANSYS and ABAQUS analyses, for a delamination initiating at ply-drop 311 and growing along interface $b l$, are compared for the GRMS model in Fig. 10. Results from the two methods are almost identical. The corresponding results for the GLMS model along interface $b l$ are presented in Fig. 11. Again, the ABAQUS and ANSYS results are similar. In both cases, as the delamination grows along $b l$, G reaches a peak and then drops, as the delamination grows between the ply and the resin pocket in front of the next dropped ply. As the delamination nears the next dropped-ply, G increases to a second peak.

\section{Delamination Onset Prediction}

In refs. 6,9 , and 14 , peak values of calculated strain energy release rates, from curves like those shown in Figs. 10 and 11, were used with measured G vs. $\mathrm{N}$ data from material characterization tests to calculate a curve that relates delamination onset and the number of loading cycles. A similar approach was used here to generate a curve that relates the maximum surface strain to the number of cycles to delamination onset. The G vs. N results for the IM7/8552 graphite/epoxy material from mode II (4ENF) tests are shown in Fig. 12, where a curve of the form $\mathrm{G}_{\operatorname{IImax}}(\mathrm{N})=908.2 \mathrm{~N}^{-0.115}$ was fit through the data. This mode II fatigue data is more comprehensive than the data available in ref. 9. Because the initial delamination growth was almost entirely mode II, this curve was considered acceptable for predicting delamination onset along the $b l$ interface. Then it was assumed that delamination would initiate in the test specimens when the peak G-value from the FE analysis equaled the cyclic $\mathrm{G}_{\mathrm{IImax}}$ at which delamination started in the 4ENF specimens; that is,

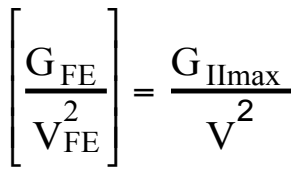

where $\mathrm{G}_{\mathrm{FE}}$ is the peak $\mathrm{G}$ for delamination along $b l$, and $\mathrm{G}_{\mathrm{IImax}}$ is the equation that was fit to the $4 \mathrm{ENF}$ data.

The term $\mathrm{V}_{\mathrm{FE}}$ corresponds to the applied transverse bending load in the model. The equation can be rewritten to solve for $\mathrm{V}$, the applied transverse load. By using the static excursion test data to relate the applied transverse load to the maximum surface strain, a calculated curve can be generated relating the maximum surface strain to the number of cycles for delamination onset. More details of this procedure are found in ref. 6. 
The calculated curve for the GRMS flexbeam is shown in Fig. 13, along with test results for the 3 GRMStype specimens. Results for the GLMS-type specimens are shown in Fig. 14. The test results exhibit reasonable agreement with the calculations. The GLMS6 specimen is shown as a runout, since testing was terminated at 2 million cycles, with no delamination detected, which appears to be consistent with the calculated curve.

In ref. 14 , the cumulative life to failure $\left(\mathrm{N}_{\mathrm{T}}\right)$ is defined as the sum of the number of cycles to create the crack between the ply-drop tip and resin $\left(\mathrm{N}_{\mathrm{M}}\right)$, the number of cycles to delamination onset from the crack at the ply-drop tip $\left(\mathrm{N}_{\mathrm{D}}\right)$, and the number of cycles to grow the delamination to a limiting size $\left(\mathrm{N}_{\mathrm{G}}\right)$. However, this study was not concerned with growth to a finite limiting delamination length, $\mathrm{N}_{\mathrm{G}}$. The life prediction curves shown in Figs. 13 and 14 are calculated assuming that there is an existing crack behind the resin pocket. That is, the calculated life is from the development of the crack to delamination onset $\left(\mathrm{N}_{\mathrm{D}}\right)$, but does not include the number of cycles to cause the crack itself to form $\left(\mathrm{N}_{\mathrm{M}}\right)$. However, it should be noted that, for the coupon flexbeams tested for this study, cracking at the ply-drop tip without any associated delamination growth was never observed. Hence, it is possible that, for these flexbeams, matrix cracking and delamination onset occur simultaneously.

\section{CONCLUDING REMARKS}

Nonlinear-tapered flexbeam laminates were cut from a full-size composite helicopter rotor hub flexbeam and were tested under combined constant axial tension and cyclic bending loads. Two different graphite/glass hybrid configurations were studied. The terminated plies were dropped in an overlapping stepwise pattern. All of the specimens failed by delaminations first starting as a crack between the tip of the

ply drop group and the adjacent resin region, and growing at the interfaces around the dropped ply toward the thick region of the flexbeam. Delaminations grew with increasing number of cyclic loads, and new delaminations formed at other ply-drop locations. A 2-D finite element model was developed representative of the flexbeam geometry, boundary conditions, and loading. The model was analyzed using two commercially available finite element computer programs, ANSYS and ABAQUS. Delaminations of various lengths were simulated in the analytical model by releasing multipoint constraints (MPCs). Strain energy release rates $(\mathrm{G})$ were calculated using the virtual crack closure technique (VCCT) using both finite element 
programs. The calculated peak $\mathrm{G}$ values were used with material characterization data to calculate fatigue life curves, for comparison with test data. An automated digital camera system was used to detect delamination onset in the flexbeams. The following observations were made based on the results:

1. Delaminations originated at a specific ply-drop near the surface and grew toward the thick end of the flexbeam. As testing continued, delaminations initiated and grew at other ply-drops, but none of the specimens failed catastrophically.

2. Images from a $1 \mathrm{~K}$ by $1 \mathrm{~K}$ digital camera did not have sufficient resolution to allow visual determination of the onset of delamination from the crack at the ply-drop tip.

3. Calculated G-values from the ANSYS and ABAQUS FE analyses with elements having similar formulations were nearly identical for delamination growth along the primary delamination interface, for both hybrid specimen types.

4. Initial delamination from the resin pocket at the ply-drop growing toward the thick region of the flexbeam is dominated by mode II.

5. A curve relating maximum surface strain to the number of loading cycles at delamination onset was calculated for each hybrid specimen type. Good agreement was obtained between tests and analyses. The calculations predict the fatigue life from the opening of the crack at the ply-drop tip until delamination onset, but do not include the cycles necessary to open the crack initially. Observations from test results indicated that delamination onset occurred shortly after, or simultaneously with, the development of the crack. 


\section{REFERENCES}

(1) Fish, JC and Lee, SW. Tensile strength of tapered composite structures. AIAA Paper No. 88-2252, Proceedings of the 30th AIAA/ASME/ASCE/AHS Structures, Structural Dynamics and Materials (SDM) Conference, Williamsburg, VA, April 1988; 324-333.

(2) Hoa, SV, Daoust, J, and Du, BL. Interlaminar stresses in tapered laminates. Polymer Composites 1988; 9(5):337-344 .

(3) Llanos, AS, Lee, SW, and Vizzini, AJ. Delamination prevention in tapered composite structures under uniaxial tensile loads. AIAA Paper No. 90-1063, Proceedings of the 31st AIAA/ASME/ASCE/AHS Structures, Structural Dynamics and Materials (SDM) Conference, Long Beach, CA, April 1990;12421252.

(4) Murri, GB, Salpekar, SA, and O'Brien, TK. Fatigue delamination onset prediction in unidirectional tapered laminates. Composite Materials: Fatigue and Fracture (Third Volume), ASTM STP 1110, T. K. O'Brien, Ed., American Society for Testing and Materials, Philadelphia;1991:312-339.

(5) Wisnom, MR. Delamination in tapered unidirectional glass fibre-epoxy under static tension loading. AIAA Paper No. 91-1142, Proceedings of the 32nd AIAA/ASME/ASCE/AHS Structures, Structural Dynamics and Materials (SDM) Conference (Part 2), Baltimore, MD; April 1991:1162-1172.

(6) Murri, GB, O'Brien, TK, and Rousseau, CQ. Fatigue life methodology for tapered composite flexbeam laminates. Journal of the American Helicopter Society;43(2);April 1998:146-155.

(7) O’Brien, TK. Towards a damage tolerance philosophy for composite materials and structures. Composite Materials: Testing and Design, Vol. 9, ASTM STP 1059, S. P. Garbo, Ed., American Society for Testing and Materials, Philadelphia;1990:7-33.

(8) Martin, RH. Incorporating interlaminar fracture mechanics into design. International Conference on Designing Cost- Effective Composites. ImechE Conference Transactions;London;September 15-16, 1998:83-92.

(9) Murri, GB, Schaff, JR, and Dobyns, AL. Fatigue and damage tolerance of a hybrid composite tapered flexbeam. Proceedings of the American Helicopter Society, Forum 54, Washington, D.C.;May 2001.

(10) ANSYS/Mechanical, Version 6.1;ANSYS, Inc.;1999.

(11) ABAQUS/Standard, Version 6.1;Hibbitt, Karlsson, and Sorensen, Inc.;2000. 
(12) Rybicki, EF and Kanninen, MF. A finite element calculation of stress intensity factors by a modified crack closure integral. Engineering Fracture Mechanics;1977;9:931-938.

(13) Raju, IS. Simple formulas for strain energy release rates with higher order and singular finite elements. NASA Contractor Report 178186;December 1986.

(14) Krueger, R., Paris, IL, O’Brien, TK, and Minguet, PJ. Fatigue life methodology for bonded composite skin/stringer configurations. Journal of Composites Technology and Research;2000;24:56-79. 


\section{Figure Captions}

Figure 1. Tapered hybrid flexbeam specimen with strain gages.

Figure 2. Edge of tapered hybrid composite specimen showing dropped plies.

Figure 3. Finite element model of flexbeam, refined mesh around dropped ply group, and local $t-n$ element coordinate system.

Figure 4. Loads and displacements in Virtual Crack Closure Technique in local coordinate system.

Figure 5. Delamination damage in GLMS3 specimen at $\mathrm{N}=61,614$ cycles.

Figure 6. Delamination at ply-ending 311 and three possible paths for delamination growth.

Figure 7. ANSYS-calculated strain energy release rates for delamination at three interfaces from ply-drop 111, in GRMS flexbeam.

Figure 8. ANSYS-calculated strain energy release rates for delamination at three interfaces from ply-drop 311 , in GRMS flexbeam.

Figure 9. ABAQUS-calculated strain energy release rates for delamination at three interfaces from ply-drop 311 , in GRMS flexbeam.

Figure 10. Calculated $\mathrm{G}_{\mathrm{T}}$ for delamination from ply-drop 311 along interface $b l$ in GRMS flexbeams.

Figure 11. Calculated $\mathrm{G}_{\mathrm{T}}$ for delamination from ply-drop 311 along interface $b l$ in GLMS flexbeams.

Figure 12. Delamination onset data and fitted curve for cyclic mode II 4ENF tests of graphite/epoxy material.

Figure 13. Calculated and measured delamination onset for GRMS flexbeams.

Figure 14. Calculated and measured delamination onset for GLMS flexbeams. 
Table 1. Typical laminae room temperature properties.

\begin{tabular}{|c|c|c|c|c|c|c|c|}
\hline Material & $\begin{array}{l}\mathrm{E}_{1 \mathrm{t}}, \mathrm{GPa} \\
\text { (Msi) }\end{array}$ & $\begin{array}{l}\mathrm{E}_{2 \mathrm{t}}, \mathrm{GPa} \\
(\mathrm{Msi})\end{array}$ & $\begin{array}{l}\mathrm{E}_{1 \mathrm{c}}, \mathrm{GPa} \\
(\mathrm{Msi})\end{array}$ & $\begin{array}{l}\mathrm{E}_{2 \mathrm{c}}, \mathrm{GPa} \\
(\mathrm{Msi})\end{array}$ & $\begin{array}{l}\mathrm{G}_{12}, \mathrm{GPa} \\
(\mathrm{Msi})\end{array}$ & $\square_{12}$ & $\begin{array}{l}\text { Thickness, mm } \\
\text { (in.) }\end{array}$ \\
\hline IM7/8552 & $\begin{array}{l}161.35 \\
(23.4) \\
\end{array}$ & $\begin{array}{l}11.38 \\
(1.65) \\
\end{array}$ & $\begin{array}{l}143.4 \\
(20.80)\end{array}$ & $\begin{array}{l}12.75 \\
(1.85) \\
\end{array}$ & $5.17(0.75)$ & 0.32 & $0.152(0.006)$ \\
\hline $\mathrm{S} 2 / 8552$ & $\begin{array}{l}47.58 \\
(6.90)\end{array}$ & $13.10(1.9)$ & $\begin{array}{l}46.88 \\
(6.80)\end{array}$ & $17.93(2.6)$ & $5.03(0.73)$ & 0.27 & $0.152(0.006)$ \\
\hline
\end{tabular}


Table 2. Flexbeam specimens and test parameters.

\begin{tabular}{|lllll|}
\hline Specimen & $\begin{array}{l}\text { Specimen } \\
\text { width, mm, } \\
\text { (inches) }\end{array}$ & $\begin{array}{l}\text { Transverse } \\
\text { stroke, V, } \\
\mathrm{kN}(\text { lbs. })\end{array}$ & $\begin{array}{l}\text { R-ratio, } \\
\square_{\min } / \square_{\max }\end{array}$ & $\begin{array}{l}\square_{\max } \\
\square \square\end{array}$ \\
\hline GRMS1 & $25.4(1.0)$ & $8.76(1970)$ & 0.13 & 8000 \\
\hline GRMS2 & $25.4(1.0)$ & $4.54(1020)$ & 0.12 & 5000 \\
\hline GRMS3 & $25.4(1.0)$ & $4.43(995)$ & 0.13 & 5658 \\
\hline GLMS1 & $25.4(1.0)$ & $5.69(1280)$ & 0.10 & 6830 \\
\hline GLMS2 & $25.4(1.0)$ & $4.45(1000)$ & 0.12 & 5600 \\
\hline GLMS3 & $12.7(0.5)$ & $2.95(663)$ & 0.10 & 5756 \\
\hline $\begin{array}{l}\text { GLMS6 } \\
\text { runout }\end{array}$ & $12.7(0.5)$ & $0.82(184)$ & 0.11 & 4500 \\
\hline
\end{tabular}




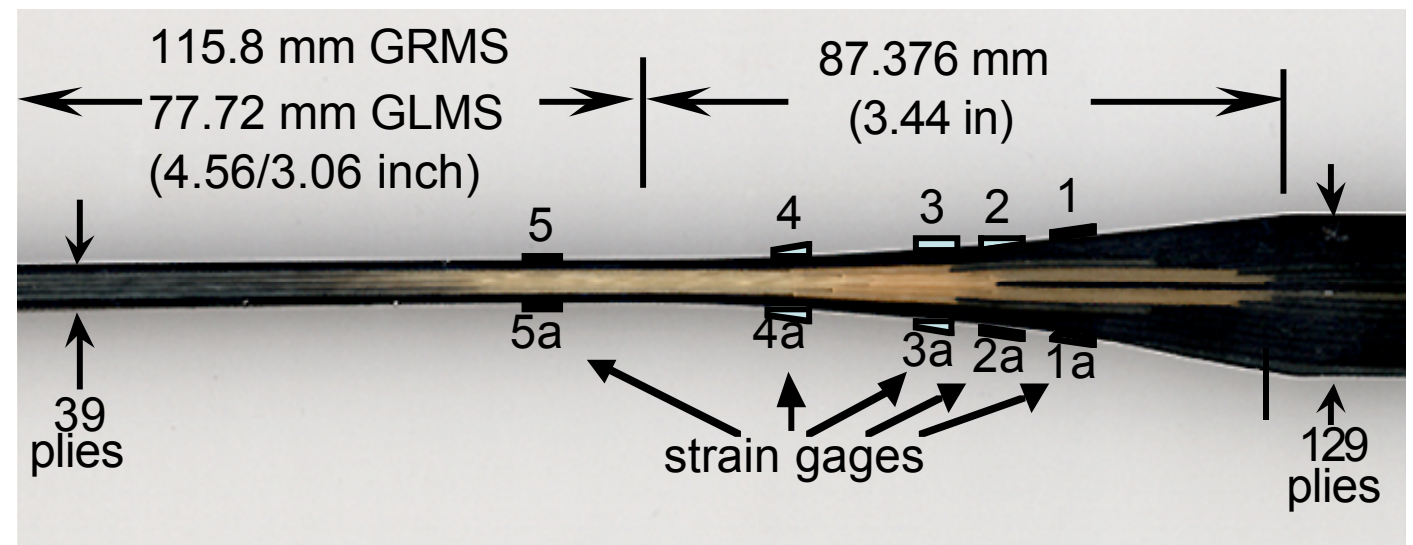

Figure 1. Tapered hybrid flexbeam specimen with strain gages. 

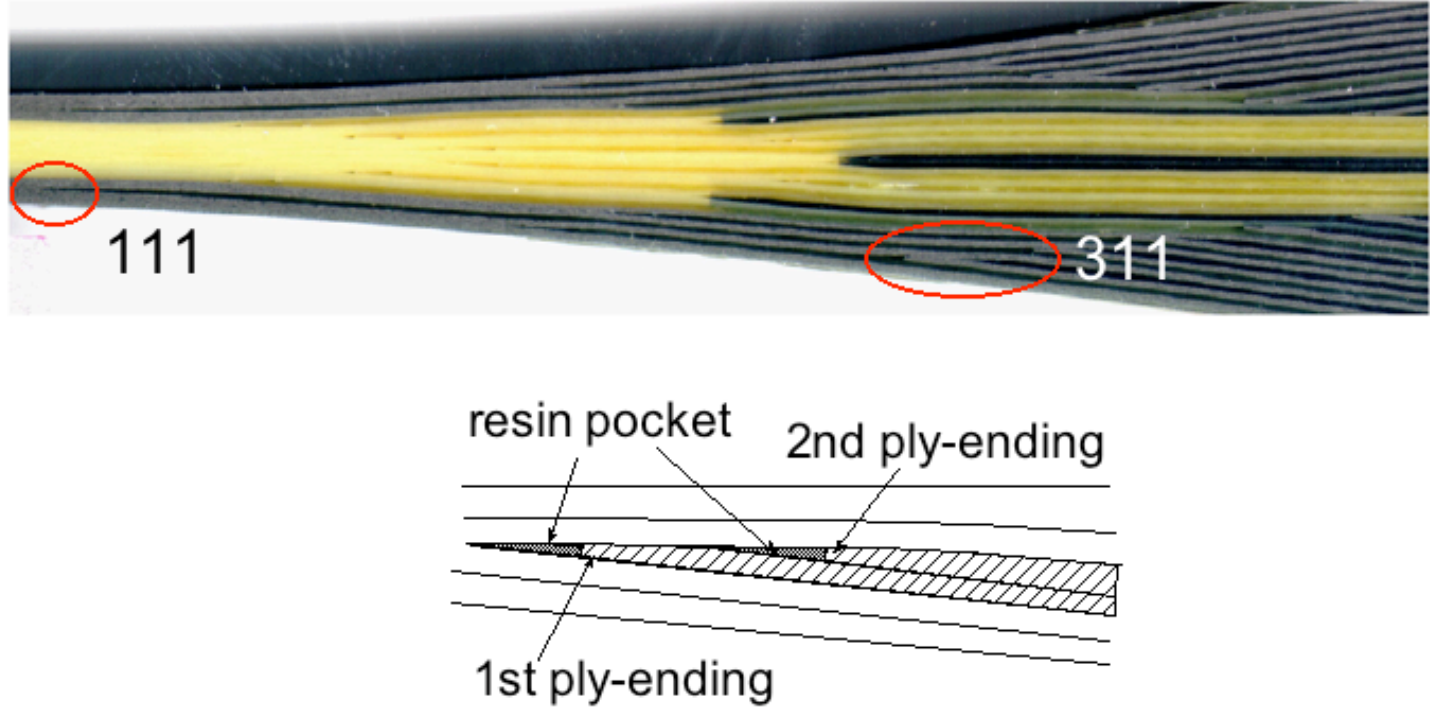

Figure 2. Edge of tapered hybrid composite specimen showing dropped plies. 


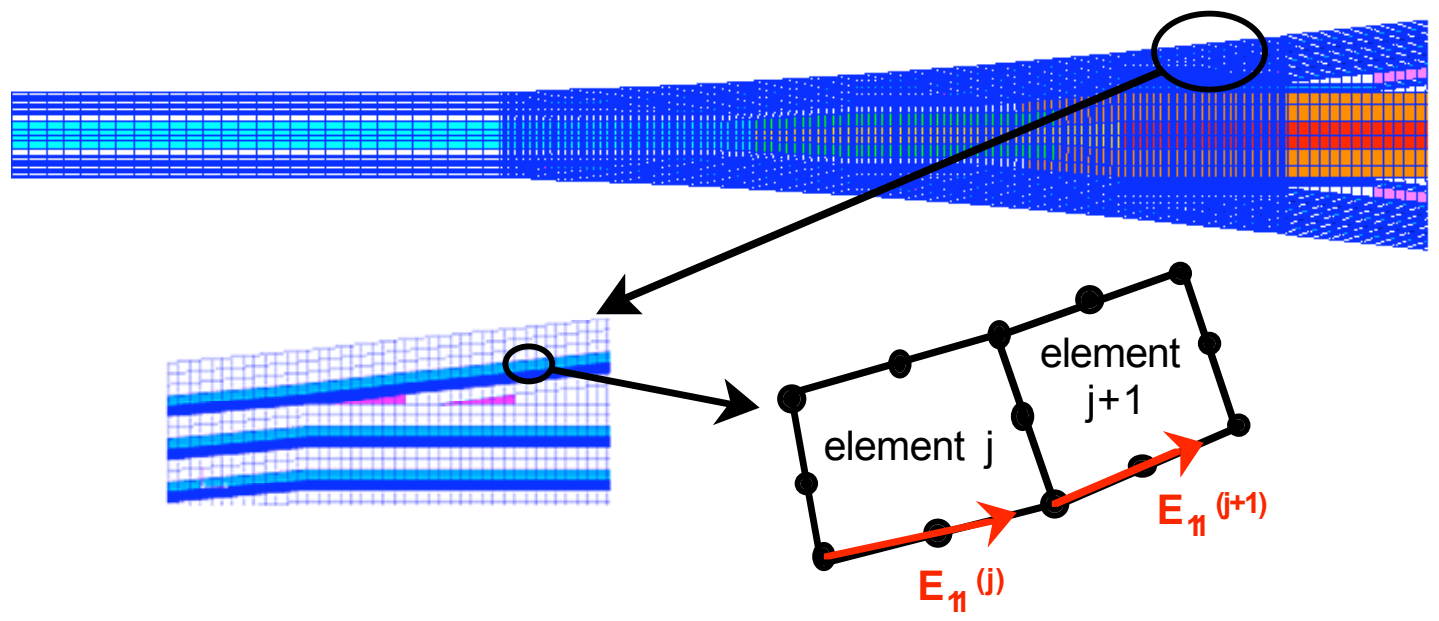

Figure 3. Finite element model of flexbeam, refined mesh around dropped ply group, and local t-n element coordinate system. 


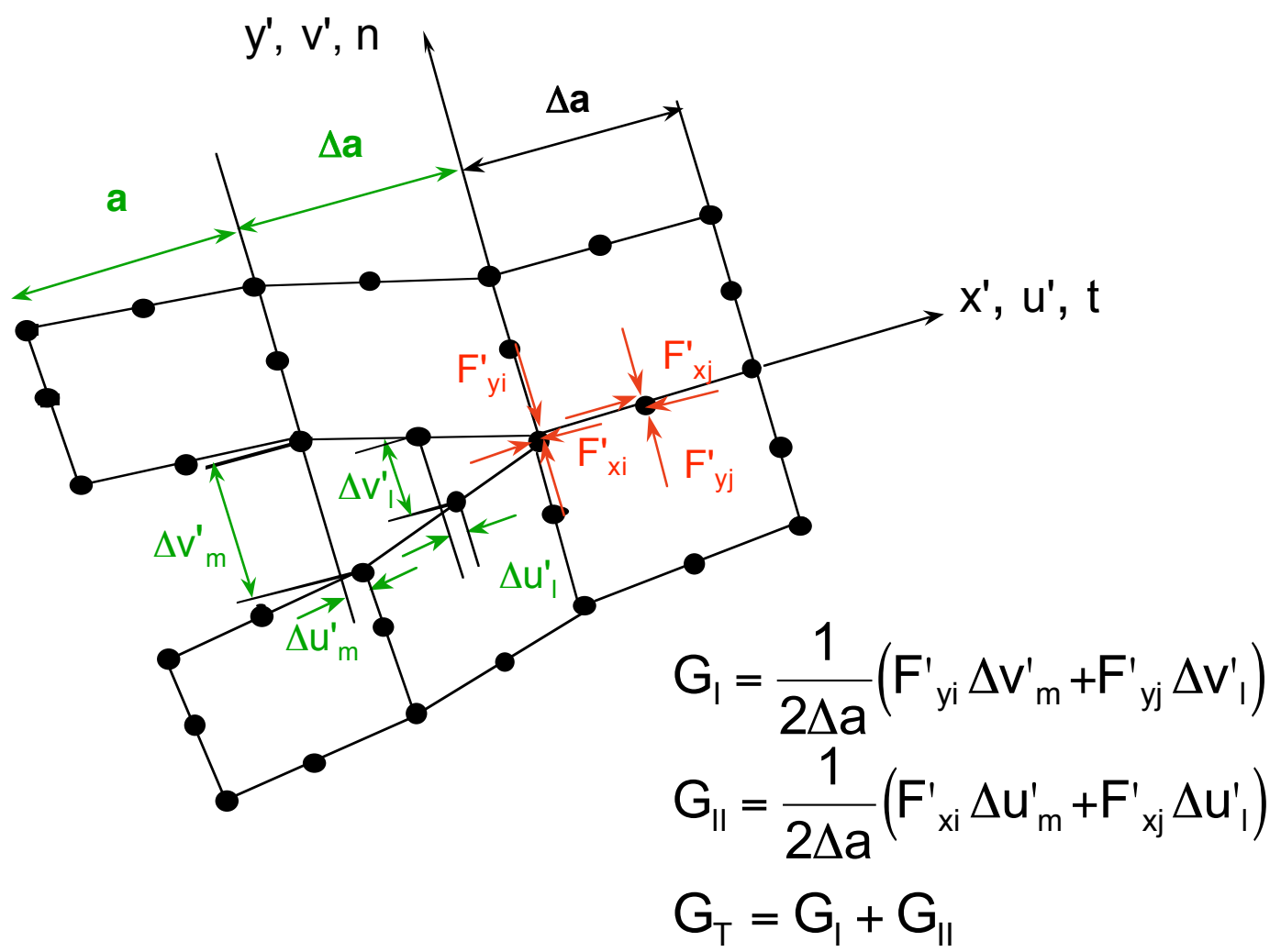

Figure 4. Loads and displacements in Virtual Crack Closure Technique in local coordinate system. 


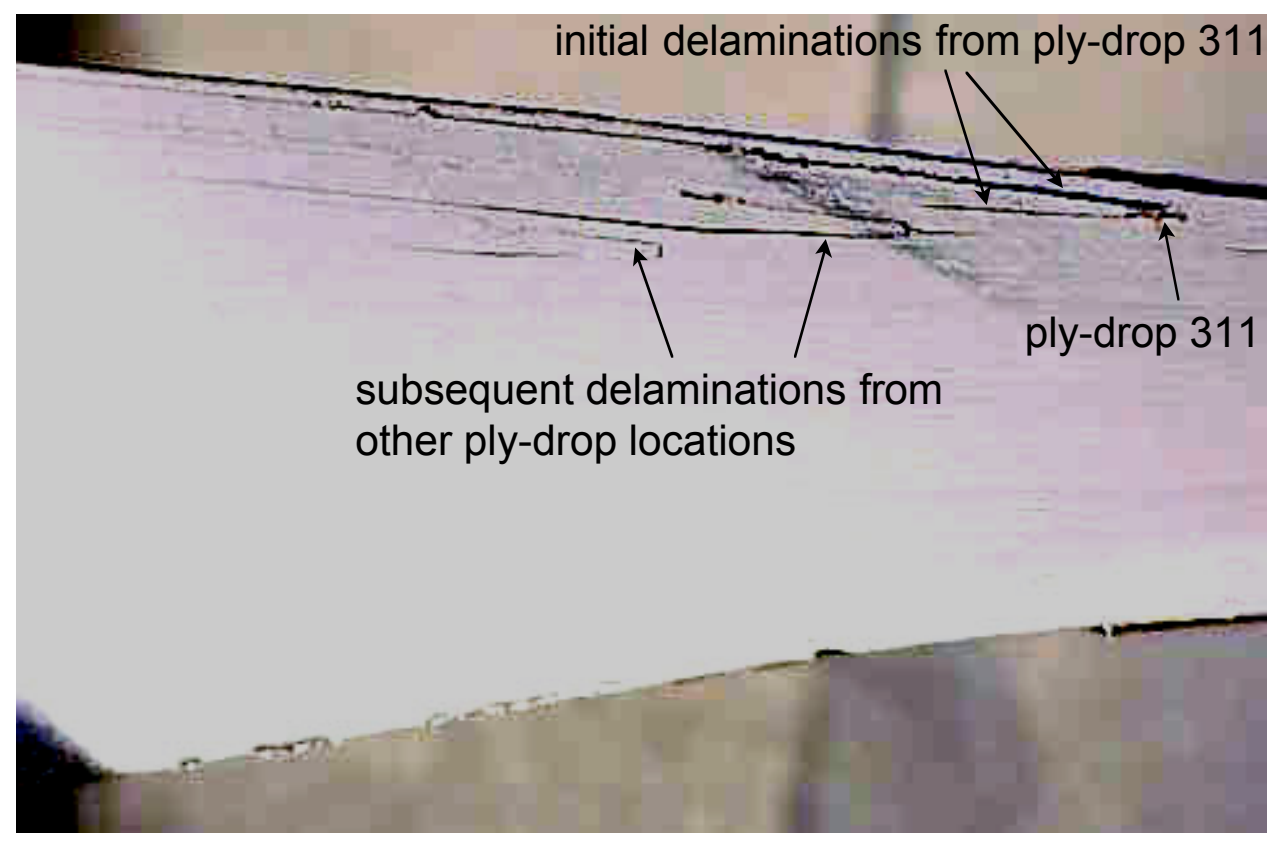

Figure 5. Delamination damage in GLMS3 specimen at $\mathrm{N}=61,614$ cycles. 

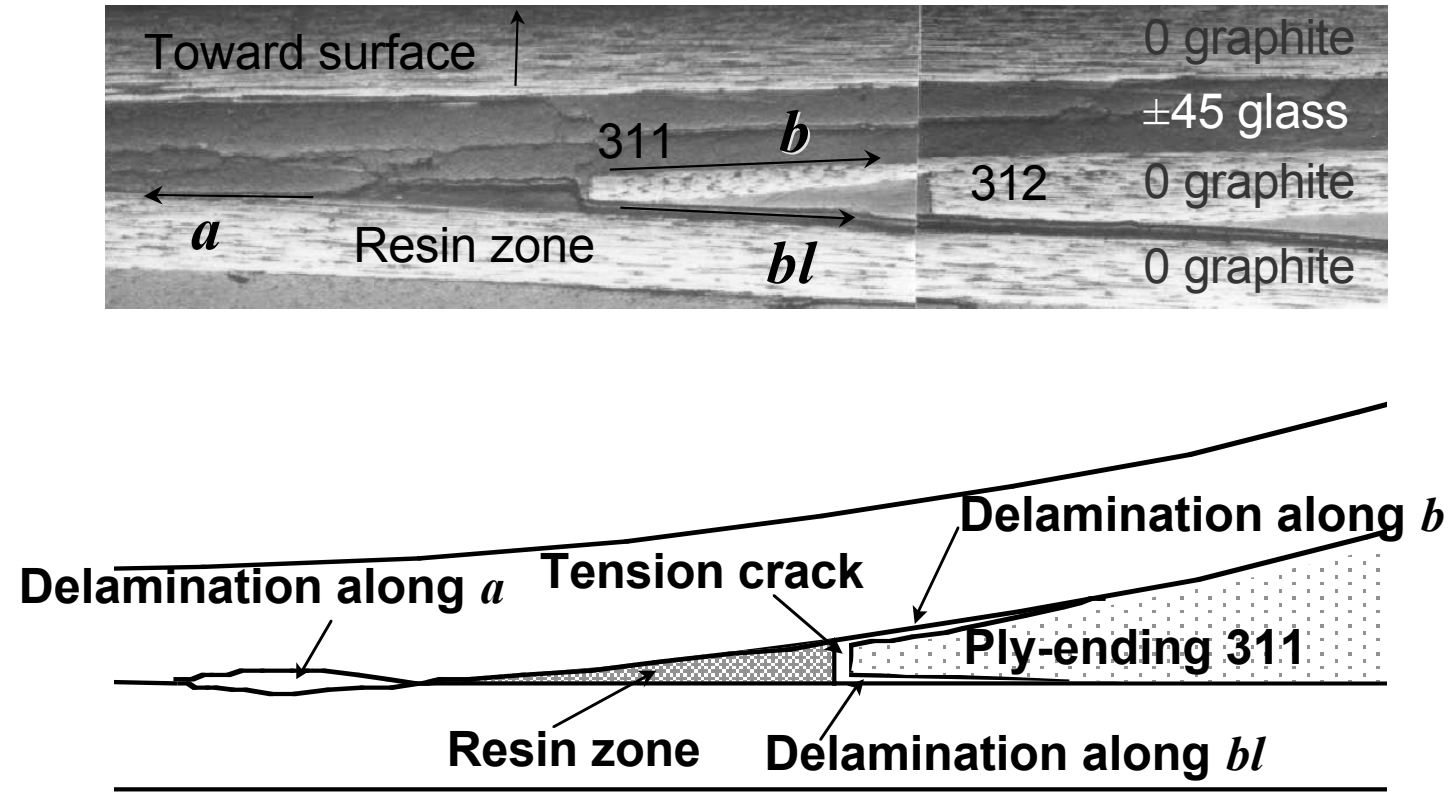

Figure 6. Delamination at ply-ending 311 and three possible paths for delamination growth. 


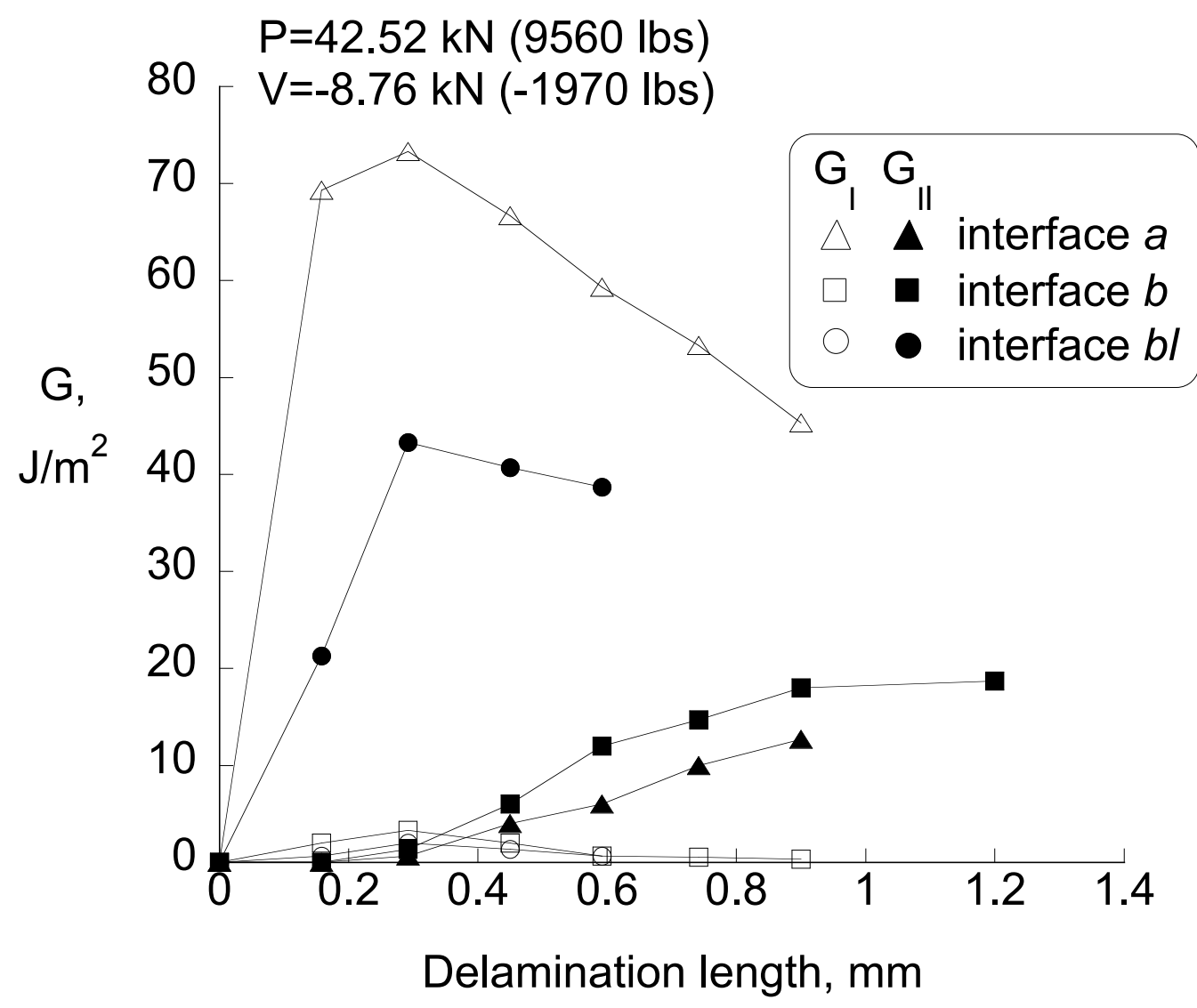

Figure 7. ANSYS-calculated strain energy release rates for delamination at three interfaces from ply-drop 111 , in GRMS flexbeam. 


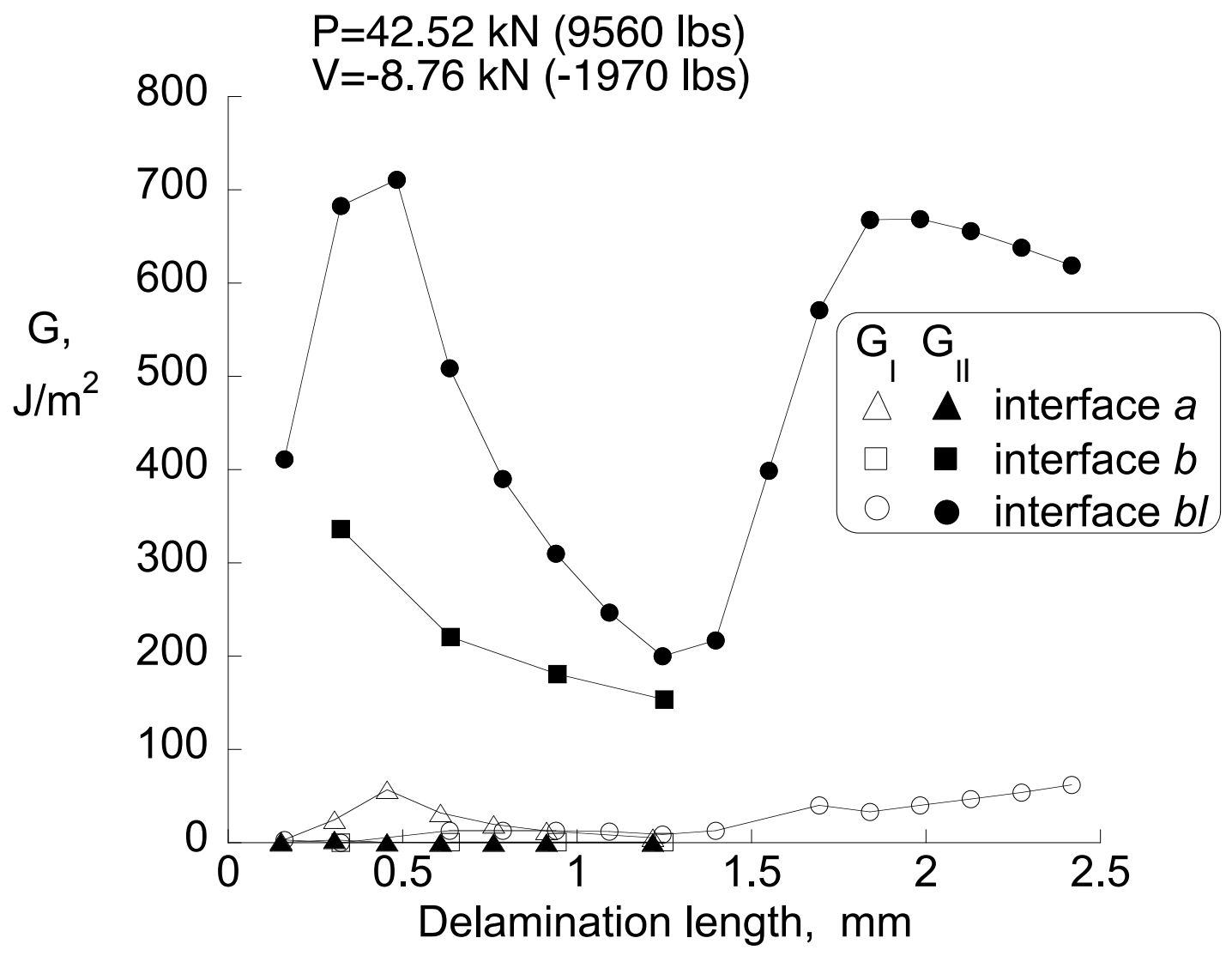

Figure 8. ANSYS-calculated strain energy release rates for delamination at three interfaces from ply-drop 311 , in GRMS flexbeam. 


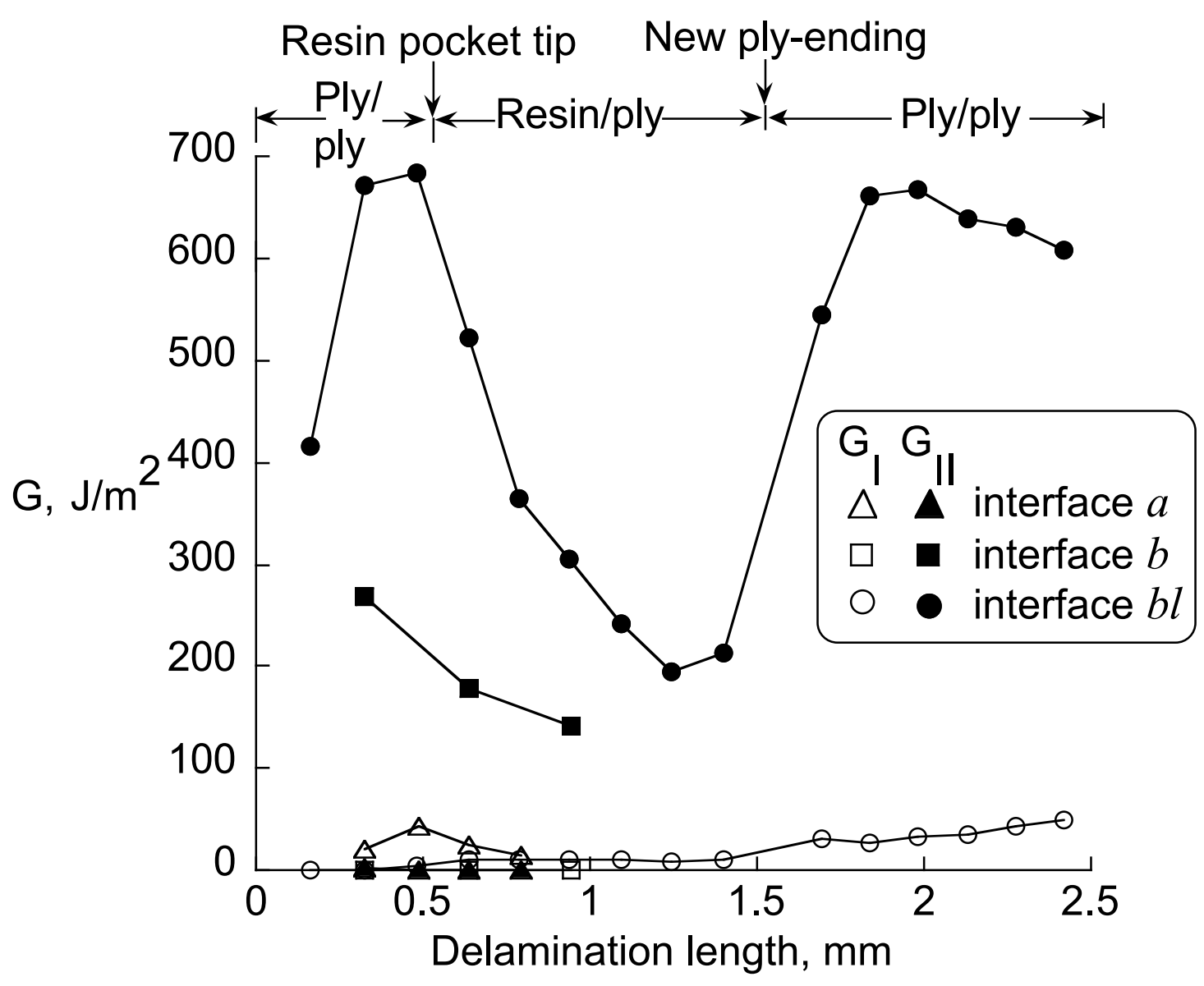

Figure 9. ABAQUS-calculated strain energy release rates for delamination at three interfaces from ply-drop 311 , in GRMS flexbeam. 


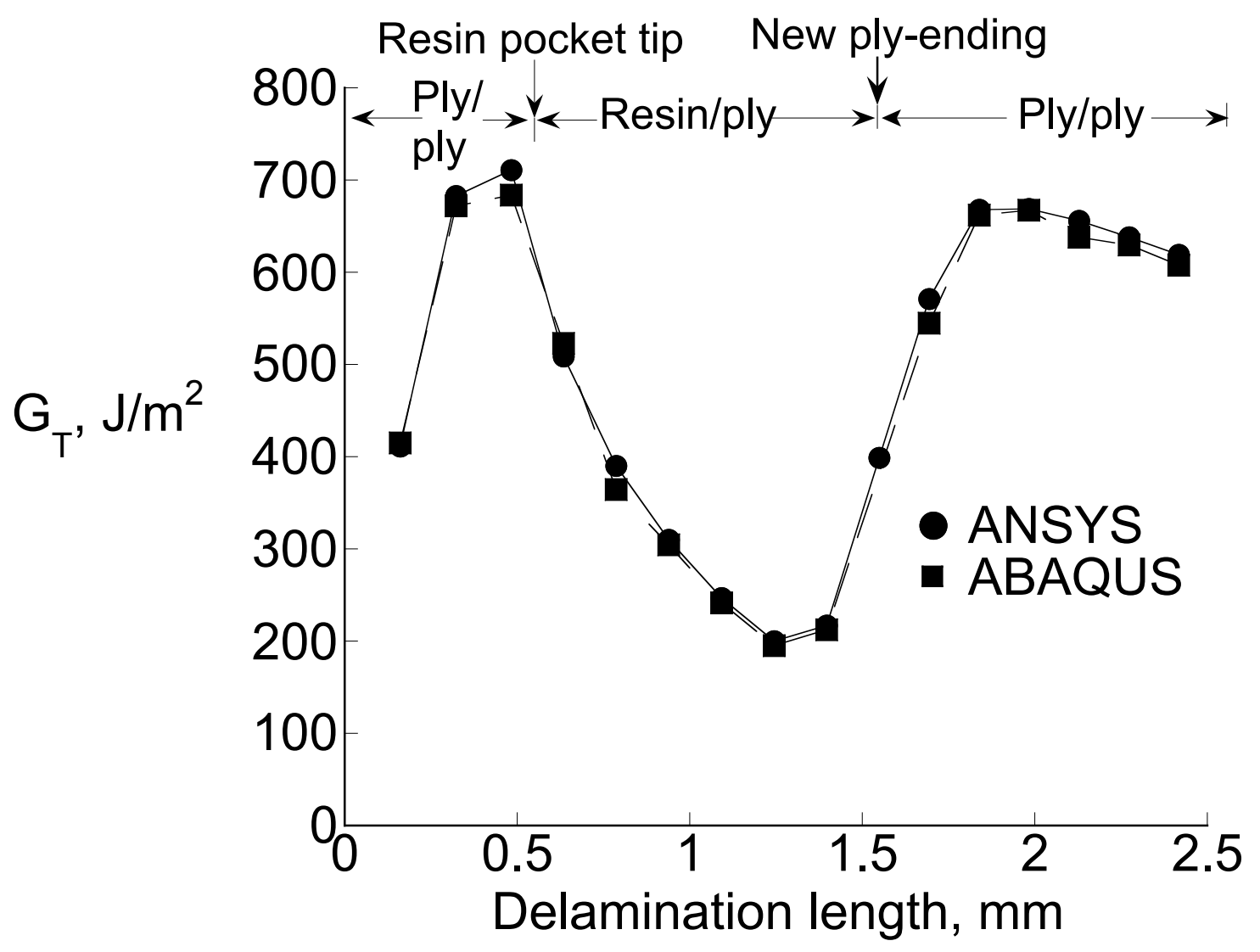

Figure 10. Calculated $\mathrm{G}_{\mathrm{T}}$ for delamination from ply-drop 311 along interface $b l$ in GRMS flexbeams. 


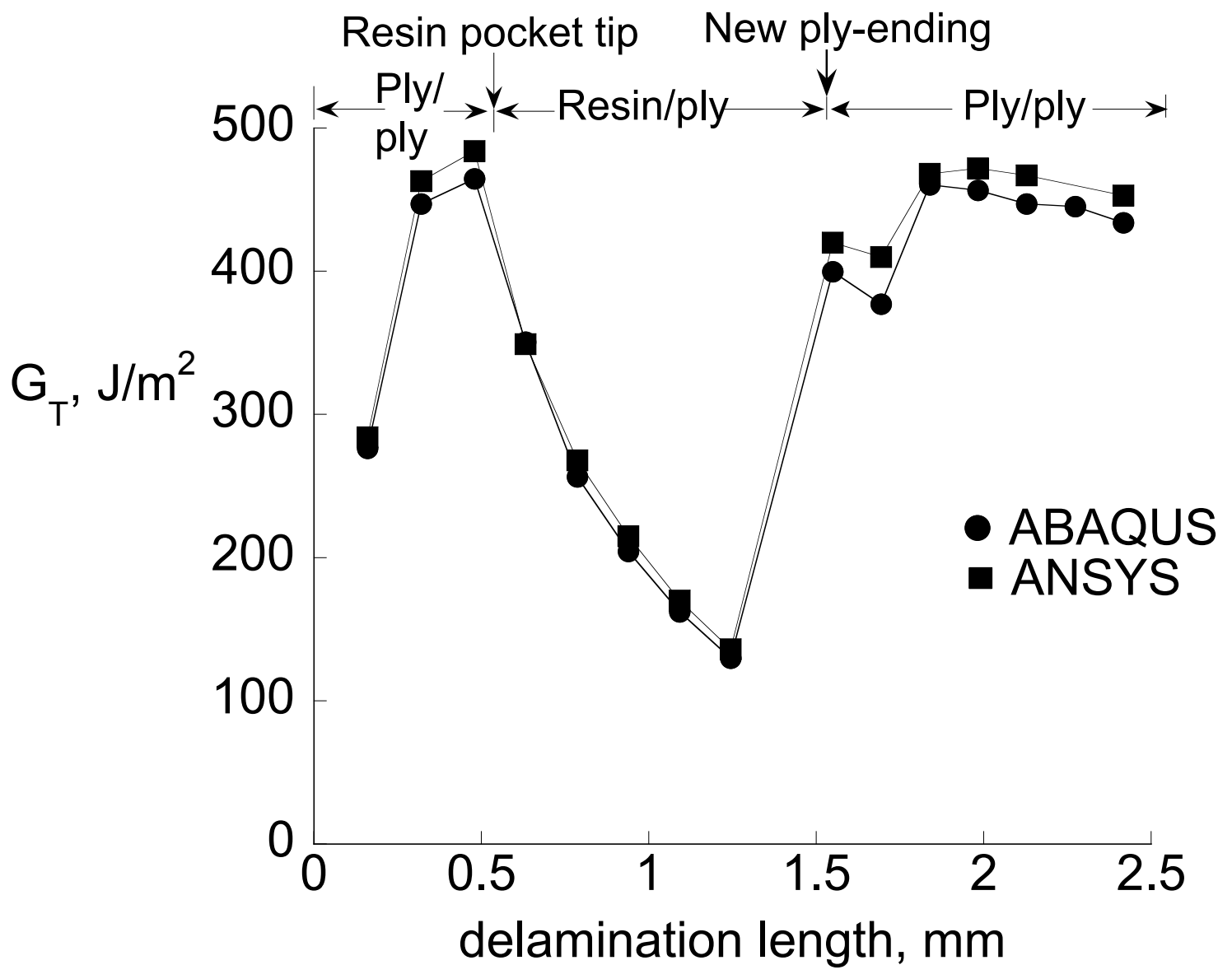

Figure 11. Calculated $\mathrm{G}_{\mathrm{T}}$ for delamination from ply-drop 311 along interface $b l$ in GLMS flexbeams. 


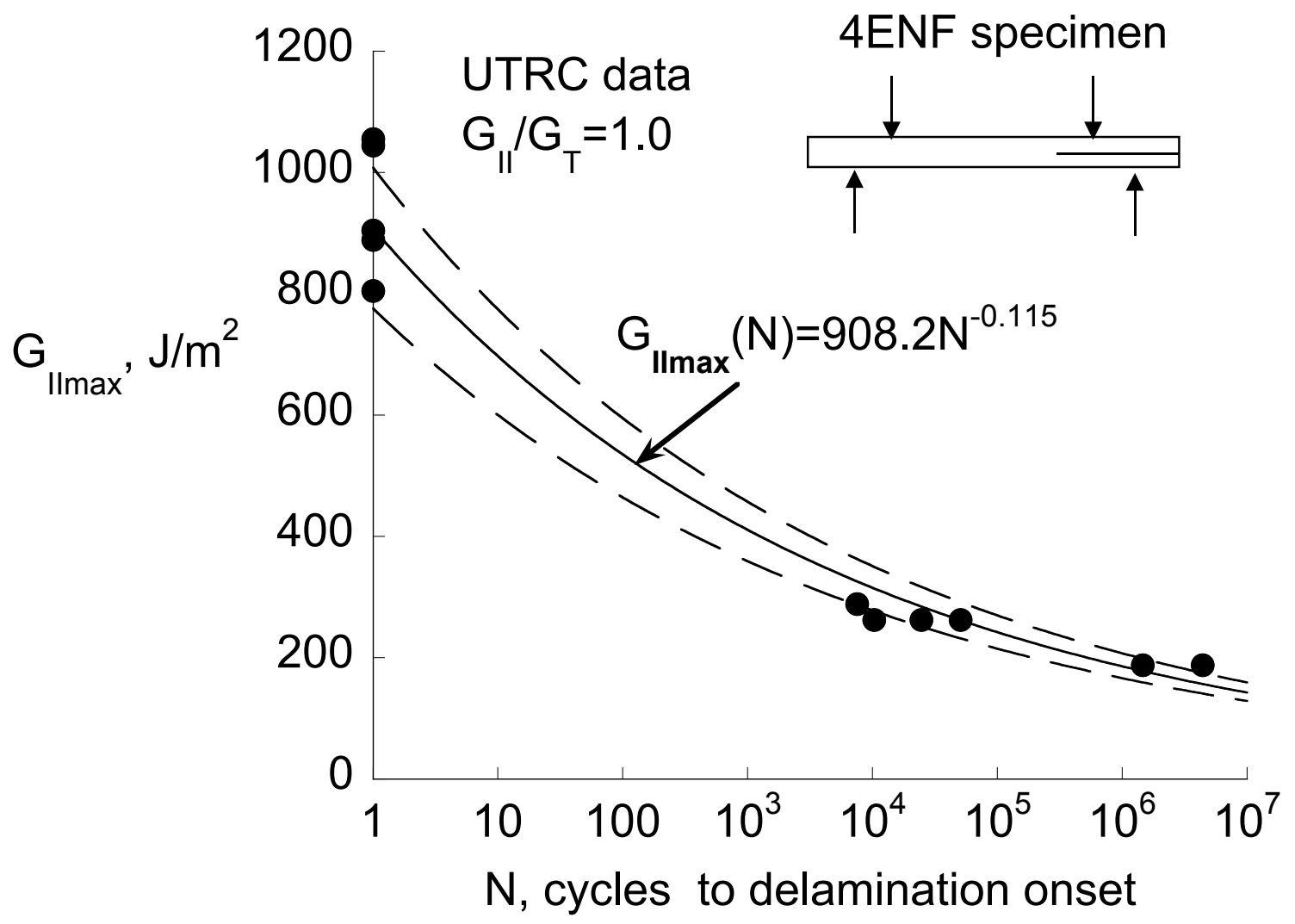

Figure 12. Delamination onset data and fitted curve for cyclic mode II 4ENF tests of graphite/epoxy material. 


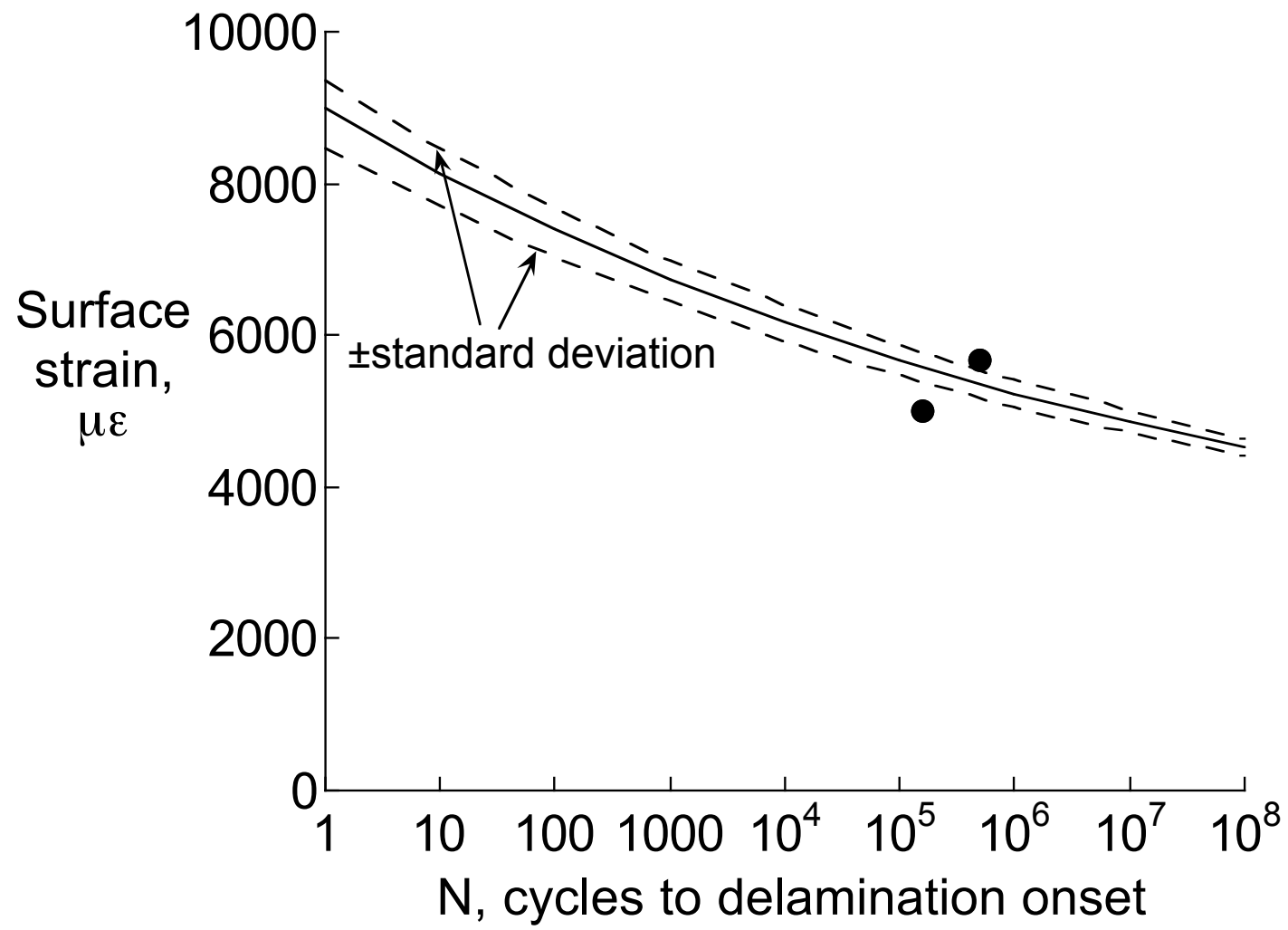

Figure 13. Calculated and measured delamination onset for GRMS flexbeams. 


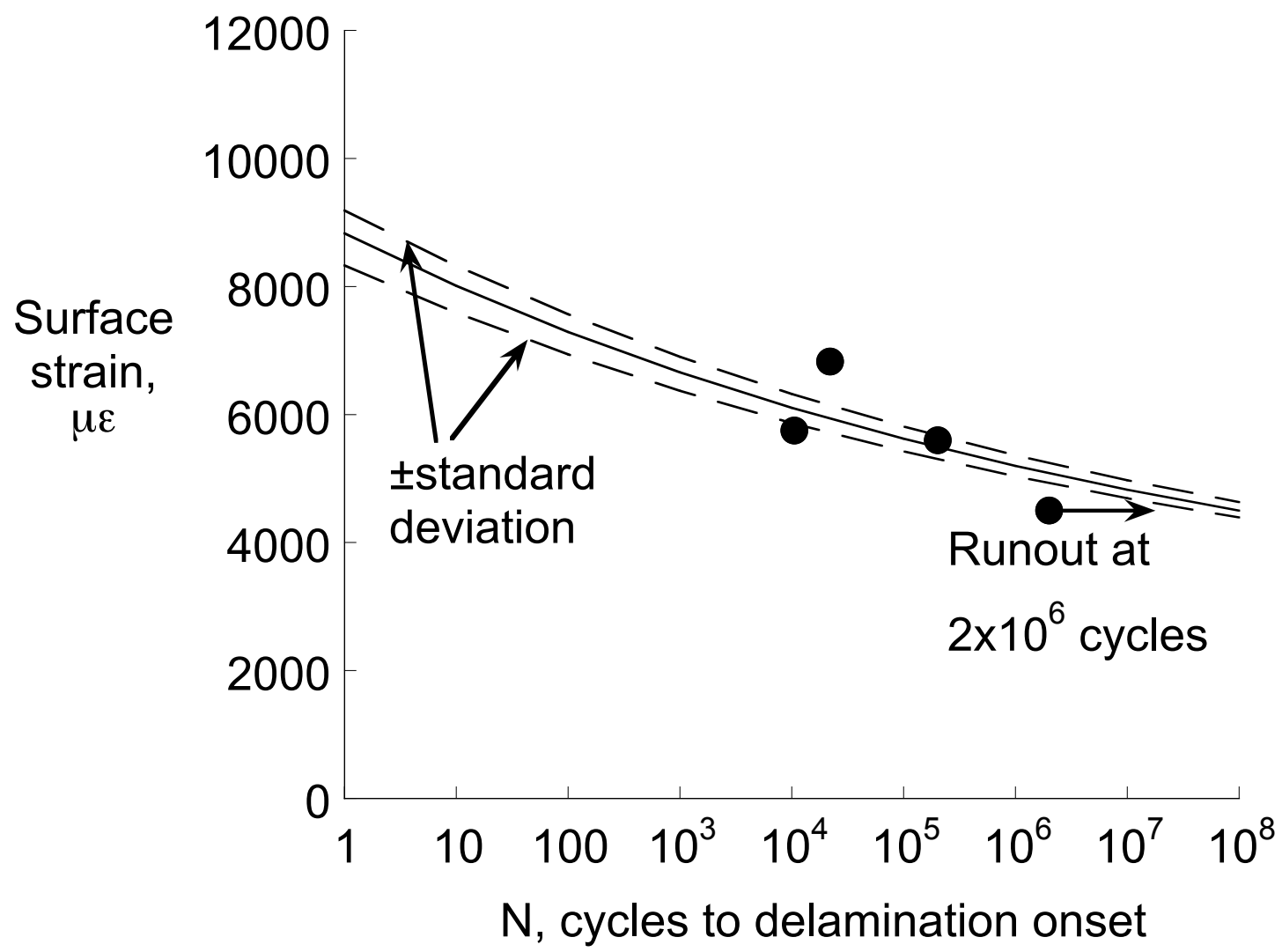

Figure 14. Calculated and measured delamination onset for GLMS flexbeams. 